REVIEW ARTICLE

\title{
Improving the Quality of Training and Service in Obstetrics and Gynecology Practice
}

\author{
Abdel-Lateef Ashmaig ${ }^{1}$, Mohammed Abdelmoneim²
}

\begin{abstract}
Improving the quality of training and service in obstetrics and gynecology practice starts at the community level [the patient and family, the midwife (MW), the community health worker (CHW)], goes through the higher levels of healthcare providers (doctors, nurses, secondary level healthcare facilities), and escalates to reach the government level. Both MWs and CHWs can play vital role in improving the quality of care provided. Task shifting, where responsibilities and tasks can be shifted from highly trained health workers to less highly trained health workers in order to maximize the efficient use of health workforce resources, needs to be appropriately addressed.

Learning objectives: To acknowledge the importance of improving the quality of training and care. To acknowledge the vital role of MWs and CHWs. To acknowledge the importance of "task shifting".

Keywords: Obstetrics and gynecology, Task shifting, Training.

Donald School Journal of Ultrasound in Obstetrics and Gynecology (2020): 10.5005/jp-journals-10009-1625
\end{abstract}

\section{INTRODUCTION}

- It is essential that we keep improving the quality of training, as this will have a profound impact on all aspects: the healthcare provider, the patient, and the healthcare facility.

- There are many levels where improvement can be continuously applied:

- The community level.

- Healthcare facility level, including the healthcare provider.

- Government level.

\section{Improvements at the Community Level ${ }^{1}$}

- Starts at the "patient" or family level, that is, by improving the awareness of different health issues.

- Should also include training and support of the Midwives (MWs) and the community health workers (CHWs). They should be targeted as they are likely to be the first-line to which the obstetric/gynecology cases present.

- Can also include "task shifting".

- Support should be at the minimum.

- Finance to the family, MW, and CHW.

- Finance for the local health facility (improving the working environment).

- By providing MW, CHW, and local health facilities with the materials they need to provide the service (e.g., vaccinations, contraception, pregnancy vitamins, simple leaflets, surgical instruments, etc.).

- By delivering basic training programs (basic practical skills, basic life support, neonatal resuscitation, sterilization and disinfection, manual vacuum aspiration, etc.).

- By making it easier to reach the health facility.

- A well-trained community MW will be able to manage the common obstetric and gynecological presentations including caring for pregnant women, managing normal deliveries,
1'Department of Obstetrics and Gynecology, Ribat University, Sudan

${ }^{2}$ Reproductive Health Care Center, Sudan

Corresponding Author: Abdel-Lateef Ashmaig, Department of Obstetrics and Gynecology, Ribat University, Sudan, Phone: +249 912301127, e-mail: profashmaig@hotmail.com

How to cite this article: Ashmaig AL, Abdelmoneim M. Improving the Quality of Training and Service in Obstetrics and Gynecology Practice. Donald School J Ultrasound Obstet Gynecol 2020;14(1):54-55.

Source of support: Ribat University

Conflict of interest: None

referring high-risk pregnancies and complicated deliveries on time, giving breastfeeding advice, providing contraception.

- A well-trained CHW can, for example, provide advice regarding sexual health, preconception, and participating in vaccination programs.

\section{Task Shifting ${ }^{2}$}

- The dramatic shortage of physicians, nurses, pharmacists, and other clinicians and health personnel makes traditional models of healthcare delivery (e.g., physician centered) an unrealistic option in many settings.

- In response to this crisis, task shifting has been increasingly promoted and studied as one strategy to address this major global health problem.

- The World Health Organization described task shifting as the rational redistribution of tasks among health workforce teams. ${ }^{1}$

- When feasible, healthcare tasks are shifted from highly trained health workers to less highly trained health workers in order to maximize the efficient use of health workforce resources.

\section{Improvements at the Healthcare Facility and Provider Level ${ }^{3,4}$}

- Many aspects can be addressed here, including training programs for the doctors, referral systems, improving the infrastructure, and improving the working environment.

(c) The Author(s). 2020 Open Access This article is distributed under the terms of the Creative Commons Attribution 4.0 International License (https://creativecommons. org/licenses/by-nc/4.0/), which permits unrestricted use, distribution, and non-commercial reproduction in any medium, provided you give appropriate credit to the original author(s) and the source, provide a link to the Creative Commons license, and indicate if changes were made. The Creative Commons Public Domain Dedication waiver (http://creativecommons.org/publicdomain/zero/1.0/) applies to the data made available in this article, unless otherwise stated. 
- Solutions must be implemented to-

- Simplify the often unnecessary complexity of delivering medical care and

- Create systems and tools that minimize errors and catch those that do occur before they can cause harm.

- Task shifting can also be implemented here.

- Henry M Lerner, MD, has described eight tools developed over time by clinicians who have worked in the field of obstetric patient safety. These tools provide some answers and concrete starting points: ${ }^{5}$

- Continuing education

- Simulation training

- Audits

- Best practice protocols

- Safety checklists

- Complete documentation, including prepared templates

- Smart medical records

- Outside review of maternity unit characteristics and performance
Improvements at the Governmental Level ${ }^{6}$

- Many aspects can be addressed here, for instance-

- Increasing the fund directed for the health system.

- Giving support for the operational research such as the maternal mortality reports and national audits.

\section{References}

1. Aveling EL, Martin G, Herbert G, et al. optimising the communitybased approach to healthcare improvement: comparative case studies of the clinical community model in practice. Soc Sci Med 2017;173:96-103. DOI: 10.1016/j.socscimed.2016.11.026.

2. Zurn P, Poz MD, Stilwell B, et al. Imbalances in the health workforceWHO, 2002

3. Dave A. Chokshi. 4 Principles for Improving Health Care Around the World. Harvard business review, 2019.

4. Health Catalyst Editors. The Top Six Examples of Quality Improvement in Healthcare, 2019.

5. Lerner HM. Eight tools for improving obstetric patient safety and unit performance. OBG Manag 2014;26(3):38-45.

6. World Health Organization. Improving the quality of health servicestools and resources. WHO 2018. ISBN 978-92-4-151508-5. 